\title{
«ЗАКОН ТЕНДЕНЦИИ НОРМЫ ПРИБЫЛИ К ПОНИЖЕНИЮ» К. МАРКСА КАК ТЕОРЕТИЧЕСКАЯ МОДЕЛЬ ТЕХНОЛОГИЧЕСКИХ ТРАНСФОРМАЦИЙ В РАННЕИДУСТРИАЛЬНОЙ И СОВРЕМЕННОЙ ЭКОНОМИКЕ
}

\author{
(c) 2020 Лихачев Михаил Олегович
}

доктор экономических наук, доцент, профессор кафедры Экономической теории и менеджмента Московский педагогический государственный университет, Россия, Москва

E-mail: olegmix71@mail.ru

В статье рассматривается известный марксистский «закон тенденции нормы прибыли к понижению» как теоретическая модель технологических трансформаций, протекавших в раннеиндустриальном обществе. Анализируются возможности и условия реализации этой тенденции как в раннеиндустриальную эпоху, так и условиях современных технологических трансформаций.

Ключевые слова: индустриальная революция, технологическая трансформация, экономический рост, марксистская политическая экономия, накопление капитала, закон тенденции нормы прибыли к понижению

Череда технологических трансформаций, которые пережила рыночная экономика начиная с самого раннего периода индустриальной революции, неизбежно отражалась на развитии экономической мысли, которая стремилась осмыслить эти процессы, предлагая теоретические модели описывающие тенденции экономического развития. С самого начала, то есть еще в рамках классической политической экономии, теоретический анализ был сосредоточен на критических моментах и противоречиях, порождаемых технологическими трансформациями. Поэтому многие теоретические модели классической политической экономии содержат в себе неоднозначную и, скорее, пессимистическую оценку тенденций, наблюдаемой ими социально-экономической динамики. К числу таких моделей можно отнести теоретические концепции Д.Рикардо, Т.Р.Мальтуса, Ж-Ш-Л. Сисмонди, Д.С. Милля и других представителей классической политической экономии $[2 ; 5 ; 6$; 8; 9; 11]. Однако наиболее радикальную модель раннеиндустриальных экономических трансформаций дает, вне всякого сомнения, теория К. Маркса, которая рассматривает конфликты и противоречия как движущие силы развития любой системы.

К. Маркс полагал, что индустриальная или, как он ее называл, капиталистическая система производства постоянно изменяет структуру использования экономических ресурсов, снижая относительную долю использования живого тру- да по сравнению со стоимостью используемых средств производства. Это, прежде всего, приводит к стабильно недостаточному уровню спроса на труд и формированию хронической безработицы («резервной армии труда»). В результате повышение заработной платы неизбежно отстает от общих темпов роста производства, что приводит к социальному расслоению и снижает долю лиц наемного труда в распределении доходов («относительное обнищание»). Одновременно рост величины и уровня безработицы вызывает абсолютное снижение жизненного уровня значительной части населения («абсолютное обнищание»). Темпы и масштабы этого процесса, по утверждению К. Маркса, определялись темпами структурных изменений, приводящих к снижению относительной доли использования живого труда в структуре общественного капитала. Если этот процесс принимает взрывной характер, как это было в эпоху промышленной революции, то масштабы социальной поляризации становятся столь значительными, что начинают угрожать стабильности общества и его социально-экономических и политических институтов. Кроме того, потеря рабочих мест значительной частью населения и существенное ограничение уровня оплаты труда, тех, кто сохранит свою занятость, автоматически ограничивает рост спроса на продукцию производства, что оказывает дополняющее негативное воздействие, снижая степень использования ресурсов и повышая угрозу кризисов перепроизводства. 
Долгосрочная тенденция нормы прибыли к понижению как результат технологической трансформации

С точки зрения К.Маркса, прибыль равна массе прибавочной стоимости, а норма прибыли рассчитывается как отношение прибавочной стоимости к массе используемого капитала. Поэтому при данной норме прибавочной стоимости (отношении массы прибавочной стоимости к переменному капиталу) норма прибыли будет зависеть от органического строения капитала (соотношения постоянного и переменного капитала). Чем выше органическое строение капитала, то есть чем выше доля постоянного капитала по сравнению с переменным, тем ниже будет норма прибыли. К.Маркс полагает, что с развитием капиталистического производства «...совершается относительное уменьшение переменного капитала по сравнению с постоянным капиталом и, следовательно, по сравнению со всем приводимым в движение капиталом» [4, с. 203]. К. Маркс объясняет это тем, что капитализму внутренне присуще стремление к усилению эксплуатации труда, к выжиманию максимального объема прибавочной стоимости из каждой единицы трудовых ресурсов. Увеличивая долю постоянного капитала в общей массе капитала, капиталисты увеличивают производительность труда и, следовательно, повышают норму прибавочной стоимости. Но, одновременно, происходит увеличение органического строения капитала, и возросшая масса прибавочной стоимости относится к большей массе капитала.

Причина этого, по мнению К.Маркса, кроется во внутреннем противоречии капитализма как экономической системы, которой «...присуща тенденция к абсолютному развитию производительных сил независимо от стоимости и заключающейся в последней прибавочной стоимости, ...тогда как, с другой стороны, его целью является сохранение существующей капитальной стоимости и ее увеличение в возможно большей степени...» [4, с. 273]. Это противоречие ограничивает возможности экстенсивного расширения производства, поскольку прирост объемов производства при возрастающих или даже постоянных издержках ведет к снижению нормы прибыли, то есть замедлению темпов накопления капитала. Поэтому для капитализма остается только один путь развития - интенсивный рост, снижающий издержки производства и увеличивающий норму прибыли. Однако, в процессе технического совершенствования производства, органическое строение общественного капитала имеет тенденцию возвышаться. И К. Маркс на основе своей теории совершенно определенно делает вывод, что «...такое постепенное возрастание постоянного капитала по сравнению с переменным необходимо должно иметь своим результатом постепенное понижение общей нормы прибыли при не изменяющейся норме прибавочной стоимости» [4, с. 232].

Подобно Д.С. Миллю, К. Маркс выделяет ряд противодействующих причин, ослабляющих действие закона: повышение степени эксплуатации труда, понижение заработной платы ниже стоимости рабочей силы, увеличение продолжительности рабочего времени, удешевление элементов постоянного капитала, внешняя торговля и рост акционерного капитала.

Первые три причины содействуют снижению стоимости рабочей силы и, следовательно, увеличивают норму прибавочной стоимости, но при этом одновременно повышают органическое строение капитала за счет сокращения размеров переменного капитала. Удешевление элементов постоянного капитала замедляет процесс его роста и, следовательно, задерживает процесс возвышения органического строения капитала. Внешняя торговля может содействовать удешевлению элементов составляющих как переменный, так и постоянный капитал. Акционерный капитал способствует ограничению межотраслевой конкуренции, исключая из нее как те отрасли, в которых органическое строение капитала более высоко по сравнению с другими. Это замедляет процесс падения общей нормы прибыли.

В принципе, К. Маркс мог предположить, что рост физического объема постоянного капитала по сравнению с объемом применяемой рабочей силы будет компенсирован, соответствующим снижением стоимости постоянного капитала. Тогда, тенденция к росту органического строения не будет проявляться в стоимостном выражении, и «Закон тенденции нормы прибыли к понижению» не имеет силы. Однако К. Маркс предполагает, что рост физических объемов используемого капитала будет опережать снижение его стоимостной величины в результате технических усовершенствований, поскольку накопление капитала и конкурентная борьба, толкающая капиталистов к наращиванию эффективности производства происходят непре- 
рывно, а технические усовершенствования, существенно снижающие стоимость элементов постоянного капитала происходят эпизодически. Поэтому К. Маркс полагает, что рост органического строения капитала должен компенсироваться главным образом за счет повышения степени эксплуатации и других факторов, вызывающих снижение стоимости переменного капитала. А этот процесс вызывает, одновременно, повышение органического строения капитала за счет сокращения размеров переменного капитала.

Получается, что один и тот же процесс, одновременно, содействует повышению нормы прибыли, через увеличение нормы прибавочной стоимости и ее снижению, через увеличение органического строения капитала. К. Маркс говорит, что поскольку «...те самые причины, которые повышают норму прибавочной стоимости... имеют тенденцию уменьшать количество рабочей силы, применяемой данным капиталом, то они же имеют тенденцию уменьшать норму прибыли и замедлять процесс этого уменьшения» [4, с. 226.].

Следовательно, динамика нормы прибыли в долгосрочном плане зависит от того, какая из двух тенденций преобладает. Если рост нормы прибавочной стоимости опережает рост органического строения капитала,- норма прибыли будет возрастать, если рост органического строения капитала опережает рост нормы прибавочной стоимости - норма прибыли будет падать. Если же обе тенденции находятся в равновесии - норма прибыли в долгосрочном плане будет поддерживаться на постоянном уровне. Следовательно, можно сформулировать условия долгосрочного равновесия капиталистической экономики и роста органического строения капитала.

Модель тенденции нормы прибыли к понижению

К. Маркс определяет норму прибыли как отношение массы прибавочной стоимости к сумме постоянного и переменного капитала. Причем все величины выражаются в условных единицах рабочего времени, соответствующих затратам простого труда. Поэтому массу прибавочной стоимости можно определить как разность новой стоимости и переменного капитала в расчете на одного занятого работника, выраженных в соответствующих количествах простого труда. В таком случае норму прибыли можно предста- вить как:

$$
\mathrm{p}^{\prime}=\frac{\mathrm{m}}{\mathrm{c}+\mathrm{v}}=\frac{\mathrm{m} / \mathrm{v}}{\mathrm{c} / \mathrm{v}+1}
$$

где w - прибавочная стоимость, создаваемая за период времени в расчете на одного занятого работника, измеренная в условных единицах рабочего времени, определяемых как затраты простого («абстрактного») труда, а с и V - величины постоянного и переменного капитала в среднем в расчете на одного работника, в том же измерении.

Дифференцируя это выражение по величинам постоянного и переменного капитала, получаем:

$$
\mathrm{dp}^{\prime}=-\frac{\mathrm{m}}{(\mathrm{c}+\mathrm{v})^{2}} \Delta \mathrm{c}-\frac{\mathrm{m}}{(\mathrm{c}+\mathrm{v})^{2}} \Delta \mathrm{v}
$$

Решая это уравнение для $\Delta \mathrm{v}$ при $\mathrm{dp}{ }^{`}=0$, получаем, что условием стабильности нормы прибыли, обеспечивающей долгосрочное равновесие, является соблюдение равенства $\Delta \mathrm{v}=-\Delta \mathrm{c}$. Применительно к случаю возвышения органического строения капитала это соотношение означает, что сохранение стабильной нормы прибыли при повышении средних затрат постоянного капитала на одного работника требует равного ему сокращения стоимости его рабочей силы. Следствием этого должно стать увеличение нормы прибавочной стоимости и сокращение доли переменного капитала в стоимости продукта. Эта тенденция является одной из существенных аспектов процесса капиталистического накопления, как он представлен в марксистской экономической теории, и рассматривается многими современными марксистами как важнейшее достижение теории К. Маркса: «Марксова теория капитала позволяет ... обосновать вывод, что при прочих равных условиях капитал стремится к относительному сокращению доли заработной платы во вновь созданной стоимости...» [3, с. 112].

При этом, очевидно, что именно возвышение органического строения капитала придает этой тенденции характер фатальной неизбежности: поддержание сложившейся средней нормы прибыли с ростом органического строения капитала требует все более высокой нормы эксплуатации.

«Закон тенденции нормы прибыли к понижению» вызвал обширную полемику и многочисленные попытки опровержения. Эмпирические 
исследования дают противоречивые результаты: рост органического строения капитала и снижение нормы прибыли в одни исторические периоды, сменяется снижением органического строения и ростом нормы прибыли в другие периоды. Общая тенденция за полтораста лет, прошедших со времени появления марксистской теории, свидетельствует скорее в пользу тенденции к понижению нормы прибыли, чем против нее [1; 2].

Опровержения путем теоретического моделирования, начиная от первых попыток М.И.Туган-Барановского [7] и, заканчивая моделью Н. Окисио [12], разработанной с применением всех тонкостей современного экономикоматематического моделирования, исходят из того, что рост органического строения капитала и, связанное с ним совершенствование технологии, не затрагивает реальную заработную плату работников. В этом случае, действительно, можно предполагать, что капиталисты будут выбирать только такие технологии, которые будут обеспечивать сохранение существующего уровня нормы прибыли или его повышение. Между тем, в марксистской теории совершенствование технологии неразрывно связано с повышением сложности труда, что, в свою очередь, увеличивает затраты на воспроизводство рабочей силы, поскольку это необходимо для повышения квалификации работников. В долгосрочном плане эта тенденция, неизбежно, препятствует снижению стоимости рабочей силы. Во всяком случае, невозможно с уверенностью утверждать, что снижение стоимости рабочей силы всегда будет достаточным для того, чтобы сохранить сложившуюся норму средней прибыли.

Сформулированный К.Марксом закон тенденции нормы прибыли к понижению ставит очень жесткие рамки для долгосрочного равновесия. Во-первых, новые технологии, вызывающие рост затрат постоянного капитала в расчете на одного работника, должны быть достаточно эффективны, чтобы обеспечить равное этому росту сокращение затрат на воспроизводство рабочей силы. А во-вторых, даже если это условие выполняется, долгосрочное равновесие все равно будет поддерживаться лишь в течение ограниченного промежутка времени. Ведь стоимость рабочей силы, формирующая затраты переменного капитала, не может упасть до нуля и, тем более, стать отрицательной. Но дело здесь не столько в формальной невозможности этого, сколько в реальной тенденции к повышению стоимости рабочей силы, которая непосредственно связана с технологическим совершенствованием производства.

Поэтому растущее органическое строение капитала будет совместимо со стабильностью нормы прибыли лишь до определенного предела. И даже если стоимость рабочей силы действительно снижается таким образом, чтобы компенсировать рост органического строения капитала и обеспечить стабильность нормы прибыли, это снижение все равно должно приостановиться. Определить момент достижения этого предела невозможно, но он неизбежно должен наступить, когда дальнейшее развитие технологии будет связано с таким повышением сложности труда, что снижение стоимости рабочей силы, вызванное снижением стоимости товаров и услуг, входящих в набор, необходимый для ее воспроизводства, будет уравновешиваться расширением состава этого набора, связанным с потребностью воспроизводства более квалифицированного труда. Поэтому если рост капиталовооруженности труда сопровождается относительным повышением стоимости постоянного капитала по сравнению с переменным, то есть повышением органического строения капитала, это неизбежно должно рано или поздно привести к снижению нормы прибыли.

Современные технологические сдвиги также в перспективе могут иметь характеристики, столь ярко проявившиеся в процессе технологических сдвигов раннеиндустриальной эпохи. Цифровизация и роботизация значительной части производственных процессов может в обозримой перспективе существенно снизить долю затрат на использование живого труда в структуре современного капитала. Замещение труда капиталом будет осуществляться во все возрастающих масштабах, и существенно изменит саму структуру спроса на труд. Вот как характеризует эту ситуацию известный американский экономист Тайлер Коуэн: «Ключевой вопрос таков: годитесь ли вы для взаимодействия с интеллектуальными машинами или нет? Или ваши профессиональные навыки дополняют компьютер, или компьютер будет лучше работать без вас?... Множество людей окажется по одну сторону этого деления и множество по другую... Третьего не дано» [10, с. 127]. По его мнению, с развитием цифровой экономики будет востребован только либо высококвалифицированный, либо низко- 
квалифицированный труд. Труд высокой квалификации будет использоваться для управления глобальными информационными системами и для их совершенствования. Низкоквалифицированный труд будет использоваться в тех сферах, где использование высокоинтеллектуальных машин будет обходиться относительно дороже. Причем этот труд также будет осуществляться под контролем сложных информационных систем. Рабочие места для среднего технического персонала, который сегодня осуществляет основную массу интеллектуального труда, сократятся до минимума, если вообще не исчезнут. А вместе с ними должен исчезнуть многочисленный класс «белых воротничков». Эта картина разительно напоминает процессы расслоения и пролетаризации периода первой промышлен- ной революции, о которой писали классики политической экономии и сам К. Маркс. При этом процесс вытеснения живого труда будет гораздо более масштабным и необратимым, поскольку применение новых технологий будет в принципе исключать участие человека в осуществлении целого ряда производственных процессов. Однако, этот же процесс может, как показывает модель К.Маркса, привести к существенному снижению нормы прибыли, которое способно затормозить процесс накопления капитала и привести к стагнации. Так что марксистская модель тенденции нормы прибыли к понижению может оказаться актуальной для нашего времени, несмотря на все проблемы и противоречия марксистской политической экономии.

\section{Библиографический список}

1. Ананьин О. Карл Маркс и его «Капитал»: из девятнадцатого в двадцать первый век // Вопросы экономики, 2007. № 9.

2. Блауг М. Экономическая мысль в ретроспективе. М.: Дело ЛТД.,1994.

3. Бузгалин А., Колганов А. Капитал в XXI веке: pro et contra. // Вопросы экономики. 2007. № 9. С. 104-120.

4. Маркс К., Энгельс Ф. Избранные сочинения. В 9 т. Т. 9. Ч. 1.- М. Политиздат. 1988.

5. Негиши Т. История экономической теории.-М., 1995.

6. Розанваллон П. Утопический капитализм. М.: Новое литературное обозрение, 2007.

7. Туган-Барановский М. И. Теоретические основы марксизма. - М.: Эдиториал УРСС, 2003.

8. Шумпетер Й. История экономического анализа. Т. 2. СПб.: «Экономическая школа», 2001.

9. Canterbey E. R. A brief history of economics. London, 2001.

10. Coven T. Average is over.- New York, 2013.

11. Heilbroner R. L. The worldly philosophers. New York, 1999.

12. Okishio N. Technical Change and the Rate of Profit // Kobe University Economic Review. 1961. Vol. 7. P. 85-99.

13. Robbins L. A History of Economic Thought. Princeton and Oxford, 1998. 